\title{
Biomass-coal Co-combustion: Opportunity for Affordable Renewable Energy
}

\author{
Larry Lin Baxter \\ Brigham Young University - Provo, larry_baxter@byu.edu
}

Follow this and additional works at: https://scholarsarchive.byu.edu/facpub

Part of the Chemical Engineering Commons

Original Publication Citation

Fuel 84 (2005) 1295-1302

\section{BYU ScholarsArchive Citation}

Baxter, Larry Lin, "Biomass-coal Co-combustion: Opportunity for Affordable Renewable Energy" (2005).

Faculty Publications. 1732.

https://scholarsarchive.byu.edu/facpub/1732

This Peer-Reviewed Article is brought to you for free and open access by BYU ScholarsArchive. It has been accepted for inclusion in Faculty Publications by an authorized administrator of BYU ScholarsArchive. For more information, please contact ellen_amatangelo@byu.edu. 


\title{
Biomass-coal Co-combustion: Opportunity for Affordable Renewable Energy
}

\author{
Larry Baxter \\ Brigham Young University \\ Provo, UT 84601
}

\begin{abstract}
This investigation explores the reasons for and technical challenges associated with cocombustion of biomass and coal in boilers designed for coal (mainly pulverized coal) combustion. Biomass-coal co-combustion represents a near-term, low-risk, low-cost, sustainable, renewable energy option that promises reduction in effective $\mathrm{CO} 2$ emissions, reduction in SOx and often NOx emissions, and several societal benefits. Technical issues associated with cofiring include fuel supply, handling and storage challenges, potential increases in corrosion, decreases in overall efficiency, ash deposition issues, pollutant emissions, carbon burnout, impacts on ash marketing, impacts on SCR performance, and overall economics. Each of these issues has been investigated and this presentation summarizes the state-of-the-art in each area, both in the US and abroad. The focus is on fireside issues. While each of the issues can be significant, the conclusion is that biomass residues represent possibly the best (cheapest and lowest risk) renewable energy option for many power producers.
\end{abstract}

\section{Introduction}

Cofiring biomass with coal simultaneously provides among the most effective means of reducing net $\mathrm{CO}_{2}$ emissions from coal-based power plants and among the most efficient and inexpensive uses of biomass. This document principally focuses on recent progress resolving technical issues associated with cofiring, but the introduction summarizes many of the primary motivations for pursuing this technology, including several that appear to be overlooked by current governmental and industrial strategic plans and policies.

The forest products industry and farming generate residues whose use as fuel represents among the most socially and environmentally beneficial biomass resources. Energy crops - crops harvested solely for their energy content - represent additional potential fuel resources in the total biomass energy potential. So long as the farming and forest products industries that produce these residues or and energy crops are conducted in a sustained manner, growing new plants at a rate greater than or equal to the harvest rate, there is no net increase in the atmospheric $\mathrm{CO}_{2}$ associated with their use as fuel. Furthermore, residues not used as fuel generally decay to form $\mathrm{CO}_{2}$ and often smaller quantities of other much more potent greenhouse gases. Therefore, redirecting the residues into a fuel stream in some cases decreases net greenhouse gas emissions even 
without counting the displacement of the fossil-derived fuels. However, the largest greenhouse gas contribution comes from the displacement of fossil fuels. The greenhouse gas reduction potential of biomass is directly associated with its sustainable production and is in no way dependent on that production being exclusifely dedicated to power production. Indeed, sustainably produced residues exhibit greenhouse gas, environmental, and economic benefits as fuels that generally exceed those of dedicated energy crops - a point that appears to be overlooked by many governmental and industrial incentive programs. Energy crops represent economically and technically more challenging fuels than most residues but are also effective in reducing $\mathrm{CO}_{2}$ when sustainably grown.

Addition of biomass to a coal-fired boiler does not impact or at worst slightly decreases the overall generation efficiency of a coal-fired power plant (Tillman, Hughes et al. 1994; Baxter, Rumminger et al. 2000). Some of the more significant potential sources of efficiency decrease include use of non-preheated air in biomass feeders, increased parasitic losses associated with generally more energy intensive fuel preparation and handling, and increased moisture content in the fuel. The first issue would likely be eliminated in a permanent installation as contrasted with a short-term demonstration test. The remaining issues are highly fuel dependent, but in general if all of the efficiency losses associated with biomass cofiring where allocated to only the biomass fraction of energy input, they would represent a $0-10 \%$ loss in biomass conversion efficiency compared to coal. Therefore, biomass-coal cofiring results in biomass conversion efficiencies ranging from 30-38 \% (higher-heating value basis), easily exceeding efficiencies in dedicated biomass systems and rivaling or exceeding the estimated efficiencies of many future, advanced biomass-based systems. Therefore, commercialization of cofiring technologies offers among the best short- and long-term solution to greenhouse gas emissions from power generation. Since cofiring is not an option in all localities, a robust biomass utilization strategy requires development of alternative technologies as well. However, the effectiveness of the cofiring option, combined with its low cost and low technical risk, should place it high on a priority list of institutions considering an array of greenhouse gas options.

Cofiring installation costs in many power plants range from $\$ 50-\$ 300 / \mathrm{kW}$ of biomass capacity (Tillman, Hughes et al. 1994; Baxter, Rumminger et al. 2000). These low costs are achievable primarily because cofiring makes use of the existing infrastructure of a power plant with minimal infrastructural changes. These costs compare favorably with essentially any other available (hydropower being regarded as largely unavailable) renewable energy option. However, with rare exception, cofiring biomass will be more expensive than fossil energy. Cofiring usually displaces fossil power without increasing total capacity, so the capital costs with which to compare the previously quoted numbers is $\$ 0 / \mathrm{kW}$ rather than the more typical $\$ 900 / \mathrm{kW}$ for coal. In cases where additional capacity is anticipated, capital costs for cofiring are much higher when, for example, induced draft fans and other common capacity limiting subsystems must be replaced or upgraded. Operating costs are also typically higher for biomass than for coal. The most sensitive factor is the cost of fuel, resulting in energy crops suffering large economic disadvantages relative to residues. Even if the fuel is nominally free at the point of its generation (as many residues are), its transportation, preparation, and on-site handling 
typically increase its effective cost per unit energy such that it rivals and sometimes exceeds that of coal. A general conclusion is that biomass cofiring is commonly slightly more expensive than dedicated coal systems. If there are no motivations to reduce $\mathrm{CO}_{2}$ emissions, the rationale for cofiring is difficult to establish. However, the biomass component of cofiring represents renewable, essentially $\mathrm{CO}_{2}$-neutral energy. In this respect, the more relevant cost comparison is that of cofiring with other renewable options. In this comparison, cofiring represents by far the cheapest means of renewable power generation in a large fraction of situations where it is feasible, feasibility being indicated by biomass resources and coal-based power plants available in the same region. Cofiring is also represents a dispatchable, rapidly deployable, low-risk, regionally indigenous, and inherently grid-compatible energy source, all significant advantages for overall grid management and power systems planning.

Cofiring represents a short-development-time, low-cost (compared to other renewable options), low-risk, high-social-benefit, energy option badly needed in energy markets of nearly every developed and many developing countries. The technology has been demonstrated at commercial scales in essentially every (tangentially fired, front-wall fired, back-wall fired, dual-wall fired and cyclone) boiler type, combined with every commercially significant (lignite, subbituminous coal, bituminous coal, and opportunity fuels such as petroleum coke) fuel type, and with every major category of biomass (herbaceous and woody fuel types generated as residues and energy crops). However, there are few long-term tests or fully commercialized preparation or handling systems.

The major technical challenges associated with biomass cofiring include:

1. fuel preparation, storage, and delivery

2. ash deposition,

3. fuel conversion,

4. pollutant formation,

5. corrosion,

6. fly ash utilization,

7. impacts on SCR systems, and

8. formation of striated flows.

Previous reports have focused on many of these issues (primarily the first five), the conclusions of which are summarized here. Three properties of biomass impact its preparation, storage, and handling properties; Biomass has low bulk energy density, is generally moist and strongly hydrophilic, and is non-friable. Biomass heating values generally are slightly over half that of coal, particle densities are about half that of coal, and bulk densities are about one fifth that of coal. This results in an overall fuel density roughly one tenth that of coal. Consequently, cofiring biomass at a $10 \%$ heat input rate results in volumetric coal and biomass flow rates of comparable magnitudes. Consequently, biomass demands shipping, storage, and on-site fuel handling technologies disproportionately high compared to its heat contribution.

Biomass produces a non-friable, fibrous material during communition. It is generally unfeasible (and unnecessary) to reduce biomass to the same size or shape as coal. In 
many demonstration plants, biomass firing occurs with particles that pass through a $1 / 4$ " $(6.4 \mathrm{~mm}) \mathrm{mesh}$, which measurements indicate results in a size distribution dominantly less than about $3 \mathrm{~mm}$. Depending on the type of biomass and preparation technique, average aspect ratios of these particles range from three to seven, with many particles commonly having much higher aspect ratios. Such particles have very low packing densities and create challenges when pneumatically or otherwise transporting biomass fuels.

These large and non-spherical particles pose challenges for fuel conversion efficiency. Coal particles of such size would not nearly burnout in a coal boiler, but there are compensating properties of biomass. Biomass yields a much higher fraction of its mass through devolatilization than does coal. Typically biomass of the size and under the heating rates typical of pc-cofiring yields $90-95 \%$ of its dry, inorganic-free mass during devolatilization, compared with 55-60\% for most coals. Devolatilization occurs rapidly and is temperature driven, therefore most biomass fuels will yield at least this fraction of mass so long as they are entrained in the flue gases. Biomass particles too large or dense to be entrained sometimes enter the bottom ash stream with little or no conversion beyond drying. However, these are generally the exception for well-tuned fuel prepation systems. Secondly, the low particle densities help biomass particles oxidize at rates much higher than coal. However, excessive moisture or excessive size particles still may pose fuel conversion problems for biomass cofiring despite these mitigating effects.

Pollutant formation during biomass cofiring exhibits all the complexities of pollutant formation during coal combustion. $\mathrm{SO}_{\mathrm{x}}$ generally decreases in proportion to the sulfur in the fuel, which is low for many (but not all) biomass fuels. $\mathrm{NO}_{\mathrm{x}}$ may increase, decrease, or remain the same, depending on fuel, firing conditions, and operating conditions. However, the $\mathrm{NO}_{\mathrm{x}}$ chemistry of biomass shows the same, complex but conceptually well understood behavior as $\mathrm{NO}_{\mathrm{x}}$ chemistry during coal combustion with the exception that biomass appears to produce much higher $\mathrm{NH}_{3}$ content and a lower $\mathrm{HCN}$ content as a nitrogen -laden product gas compared to coal. Some of the commercially most mature biomass fuels, notably wood, contain relatively little fuel nitrogen and cofiring with such fuels tends to decrease total $\mathrm{NO}_{\mathrm{x}}$. However, general industrial experience is not consistent with the sometimes suggested truism (Tillman, Hughes et al. 1994; Baxter, Rumminger et al. 2000) that $\mathrm{NO}_{\mathrm{x}}$ reduction when cofiring biomass exceeds the fuel nitrogen displacement effect by $10 \%$. Biomass fuels also commonly contain more moisture than coal, decreasing peak temperatures and leading to commensurate decreases in $\mathrm{NO}_{\mathrm{x}}$.

Results from the remaining issues summarized above are illustrated in this document. However, the general conclusion does not change; Cofiring biomass with coal introduces several significant issues into boiler operation that have the potential for deleterious effects but none of these issues represents an insurmountable obstacle for biomass.

\section{Results}

This document discusses recent progress in the last four of the issues listed in the Introduction as major technical considerations when cofiring biomass with coal. 


\section{Corrosion}

Figure 1 and Figure 2 indicate previously reported results (Junker, Fogh et al. 1998; Robinson, Junker et al. 1998; Robinson, Junker et al. 2002) illustrating how sulfur from coal helps mitigate chlorine-based corrosion in boiler deposits from biomass. The principal result is that alkali chlorides that sometimes condense from chlorine-laden biomass fuel flue gases react with $\mathrm{SO}_{2}$, generated primarily from coal, to form alkali sulfates, which are significantly less corrosive. Figure 3 illustrates theoretical (equilibrium) predictions that illustrate that this only occurs under oxidizing conditions. Under reducing conditions, chlorides, not sulfates, and the stable form of alkali species under typical boiler heat transfer conditions. Therefore, the ameliorating effects of coalderived sulfur on corrosion during cofiring do not occur in regions of boilers where deposits are exposed to reducing conditions. Further experimental data indicates that even under oxidizing conditions, chlorine deposits may persist for many hours if deposit temperatures are very cool, reducing the kinetic rates of conversion to sulfates.

\section{Fly Ash Utilization}

The concrete market presents among the best fly ash utilization opportunities for coalderived fly ash. However, the ASTM specification (ASTM Standard C618) for use of fly ash in concrete requires that the fly ash be derived entirely from coal combustion. Many processes in modern boilers result in coal fly ash mingled with other materials, including ammonia from pollutant control devices, sorbents or other injected materials from scrubbers, residual sulfur or other compounds from precipitator flue gas treatments, and fly ash from cofired fuels such as biomass. There is a broad, but not universal, recognition that the standard should be modified, but it is not clear what modifications should be made. Here some preliminary results regarding the impact of biomass-derived ash on concrete properties are presented.

This systematic investigation of the impact of biomass- and coal-derived fly ash on concrete involves both Class $\mathrm{C}$ (subbituminous) and Class $\mathrm{F}$ (bituminous) fly ash as well as similar fly ashes mingled with herbaceous and woody biomass fly ash. In all cases, $25 \%$ of the cement originally used in the concrete is displaced by fly ash, with the fly ash containing 0-40\% biomass-derived material. Tests of concrete air entrainment, flexural strength, compressive strength, set time, freeze thaw behavior, and chlorine permeability determine the extent of the biomass impact. Only selected results are presented here and, as the tests require up to a year to conduct, all results are preliminary. The focus is on the herbaceous biomasses, since many woody fuels contain so little ash that practical cofiring is not likely to have a measurable impact on fly ash properties.

Figure 4 illustrates the impact of fly ash on the required amount of aerating agent to establish ASTM-compliant air entrainment levels in concrete. Air entrainment in concrete is essential to prevent failure during freeze-thaw cycles. As is apparent, the amount of aerating agent increases with increasing herbaceous biomass content. This dependence arises from the effect of water soluble components (higher in herbaceous biomass than in coal fly ash) tying up the aerating agent (generally surfactants), preventing them from forming films that support bubble growth. The impact illustrated is of minor economic concern but is of major process concern. That is, if fly ashes from cofired units were 
treated the same way as fly ashes from coal, the resulting concrete would likely fail under freeze thaw cycles. Increasing the surfactant to an acceptable level is of little economic impact, but failure to recognize the need to adjust it is of major impact.

Figure 5 illustrates the impact of biomass-coal commingled fly ash on flexural strength. In these test little significant difference is seen among the various samples. Additional data on set time and compressive strength indicate that all fly ashes delay set time by 2-4 hours compared to concrete made from cement only but the biomass-containing fly ash does not delay set times significantly more than the non-biomass containing fly ash. Early compressive strength (in the first month or so) is compromised by all fly ashes, again with the biomass-containing fly ash similar to coal fly ashes. However, late strength (longer than 2 months or so) is enhanced by the presence of all fly ashes.

In conclusion, there appear to be only manageable impacts of biomass-containing fly ash on concrete properties based on these preliminary data, with amount of aerating agent being an example of one issue that requires monitoring. Otherwise, biomass-containing fly ash behaves qualitatively similar to coal fly ash with no biomass in terms of structural and performance properties when incorporated into concrete.

\section{Formation of Striated Flows}

Many boilers do not mix flue gases effectively in furnace sections, resulting in gas compositions near the boiler exit that reflect burner-to-burner variations in stoichiometry and other properties. The impact of such behavior during cofiring can be an issue if one is hoping, for example, that sulfur from coal will mix with biomass-derived flue gases to ameliorate corrosion. Biomass is commonly injected in only a few burners. If the gases do not mix thoroughly, many regions of the boiler will be exposed to much higher biomass cofiring percentages than suggested by the overall average.

Advanced computational fluid mechanics models illustrate the impact of striations on ash deposition. Figure 6 illustrates the deposition patterns predicted on superheater tubes under conditions where such striations exist. As illustrated, there are large local variations in the rate of deposit accumulation. These arise from lack of complete mixing and striation in gas composition, gas temperature, gas velocity, particle loading, and other similar properties (not illustrated). Such results are highly system dependent but are believed to be a common feature of biomass-coal combustion as well as both dedicated coal and dedicated biomass combustors.

\section{Impacts on SCR Systems}

Essentially none of the cofiring demonstrations conducted in the US was performed on SCR-equipped boilers, but several tests from Europe have been conducted on such boilers. The evidence from these tests is that cofiring biomass with coal results in significant deactivation of SCR catalysts. The reasons for this deactivation are not definitive, but laboratory analyses confirm that alkali and alkaline earth metals are significant poisons to vanadium-based catalysts (which would include all commercial SCR systems) when the metals are in intimate association with the catalyst. Essentially all biomass fuels contain high amounts of either alkali or alkaline earth metals or both as 
a percentage of ash. Some biomass fuels, however, have remarkably low ash contents, clean heartwood such as sawdust being a classical example. It is possible that the commercially observed SCR deactivation arises from such poisoning or from catalyst fouling, which is also associated with such poisoning.

Figure 7 illustrates results from surface composition analyses from a catalyst exposed to the slipstream of a combustor firing alkali- and alkaline-earth-rich fuels. These normalized compositions and detection limits show that this catalyst, which experienced significant deactivation, is enriched in sulfur and alkali and alkaline earth metals after exposure relative to the pre-exposure concentrations. By contrast, the surface vanadium content decreased (by dilution). These results are consistent with the general hypothesis that alkali and alkaline earth metals can cause catalyst deactivation, but they do not indicate by what mechanism such deactivation occurs.

This issue will become increasingly important as increased numbers of boilers install SCR system to comply with lower $\mathrm{NO}_{\mathrm{x}}$ emission limits. The authors are engaged (with others) in several investigations to more fully explore this phenomenon, including advanced laboratory and field tests.

\section{Conclusions}

Biomass cofiring with coal represents an attractive option for reducing greenhouse gas emissions from coal-fired boilers. In general, there are compelling reasons to pursue this option as reviewed in the Introduction. However, there are many issues that, if not carefully managed, could compromise the boiler or downstream processes. Results to date indicate that these are all manageable but that they require careful consideration of fuels, boiler operating conditions, and boiler design. 


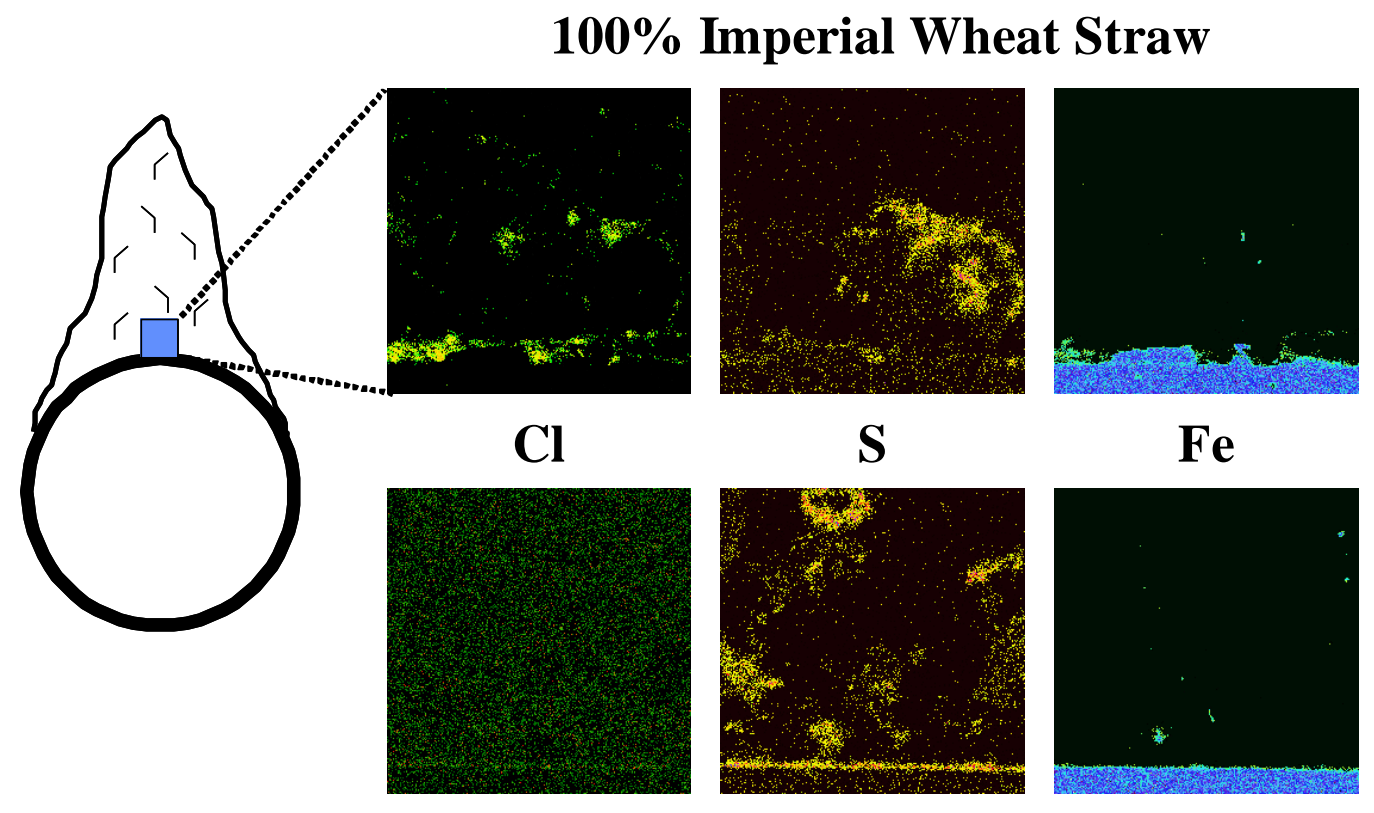

\section{$85 \%$ E. Kentucky $15 \%$ Wheat Straw}

Figure 1SEM images illustrating formation of chlorine layers on simulated boiler tubes and the effect of coal-derived sulfur during cofiring in eliminating the chlorine layers (Junker, Fogh et al. 1998; Robinson, Junker et al. 1998; Robinson, Junker et al. 2002). 


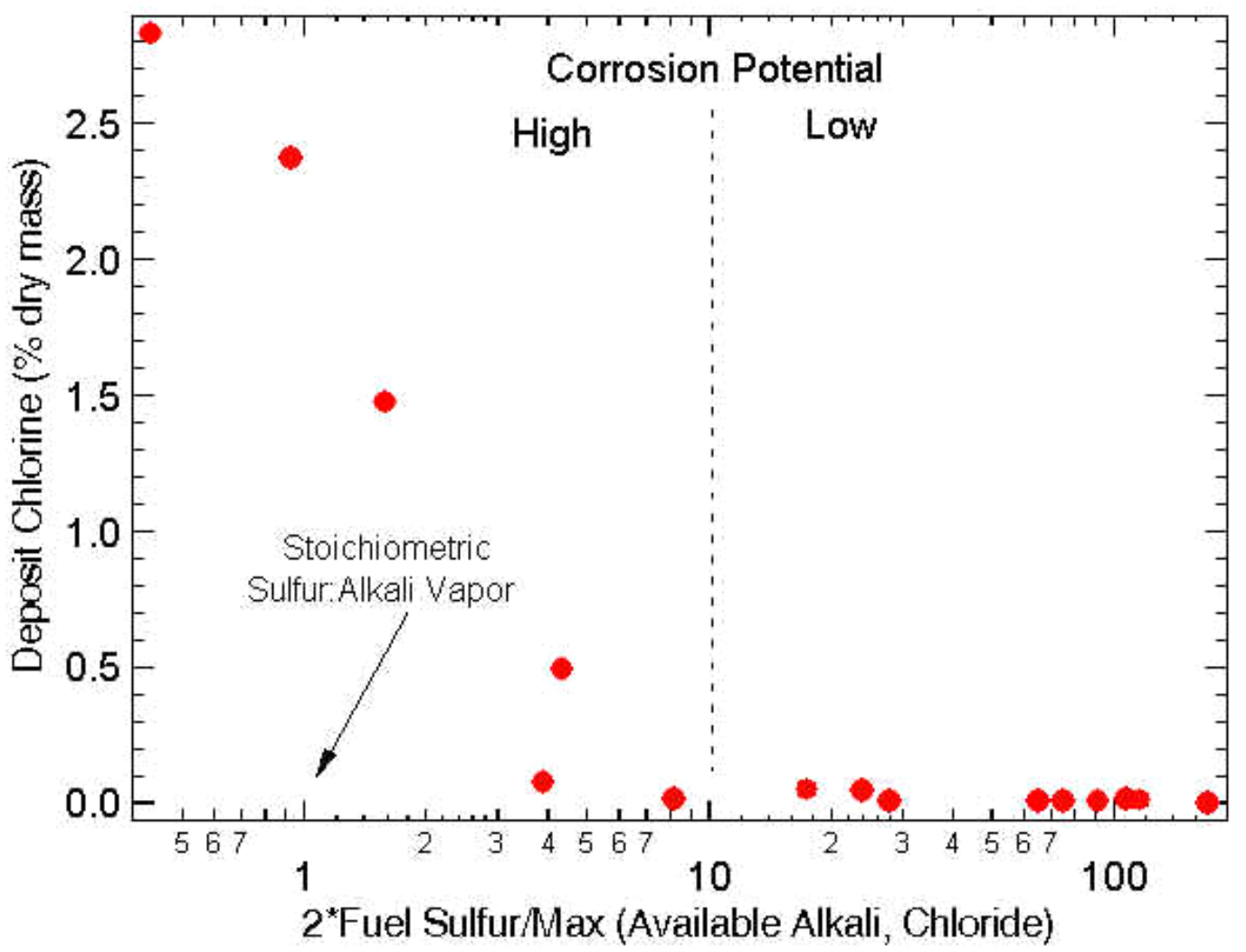

Figure 2Results from systematic variation of fuel chlorine to sulfur ratios and the resulting chlorine content of deposits under standardized testing conditions (Junker, Fogh et al. 1998; Robinson, Junker et al. 1998; Robinson, Junker et al. 2002). 


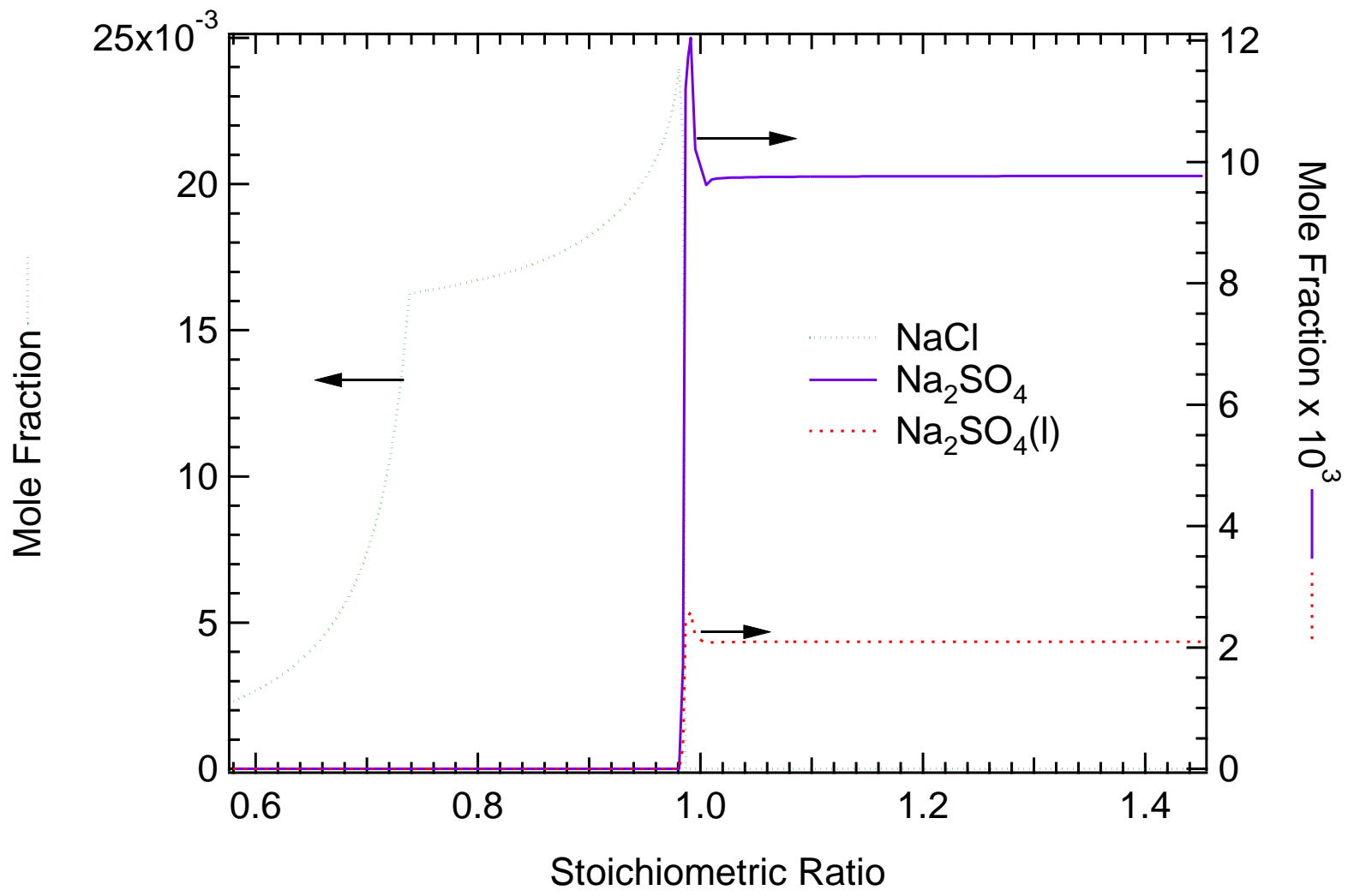

Figure 3 Illustration of predicted stoichiometric dependence of chlorine concentration in deposits.

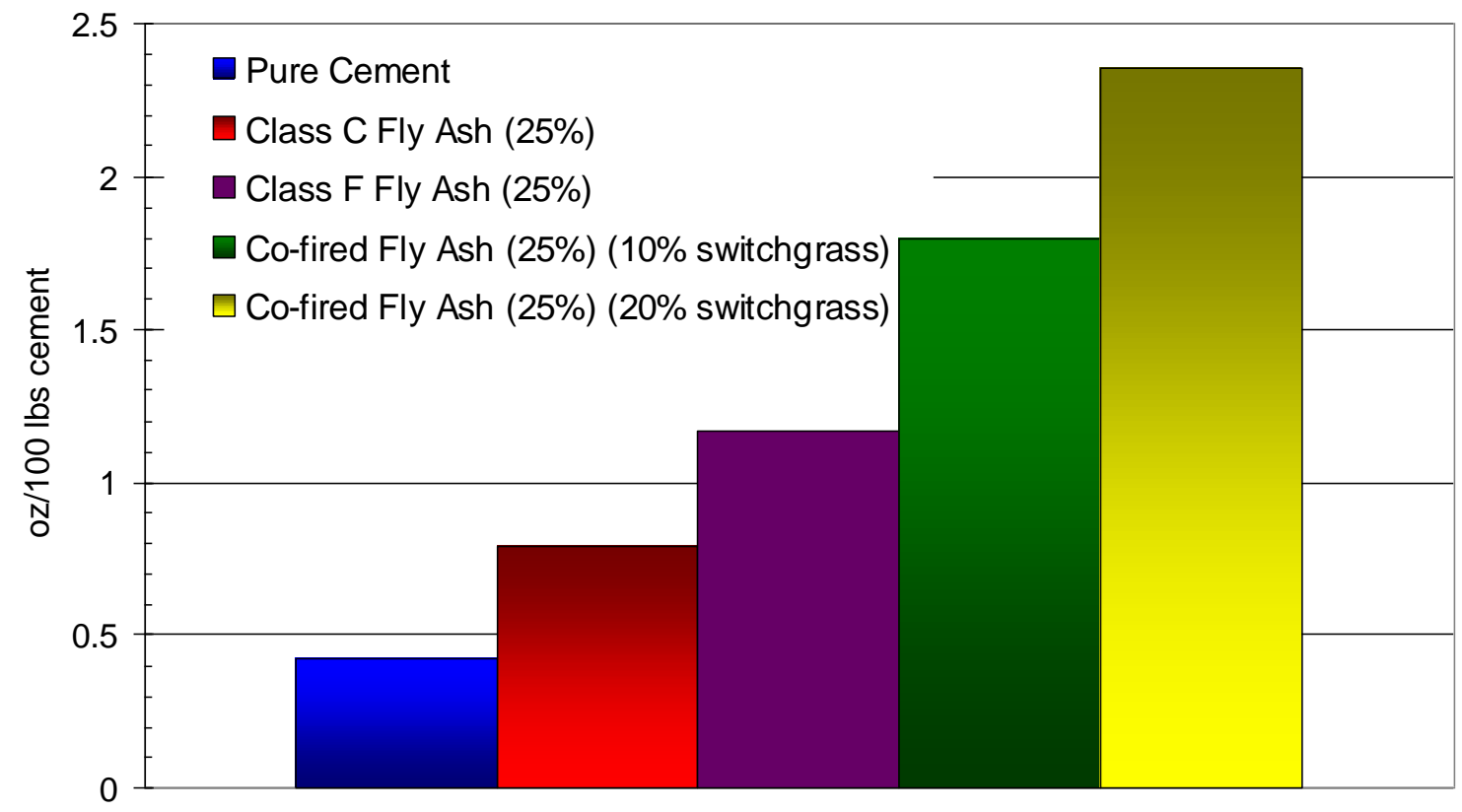


Figure 4Required amount of aerating agent required to generate air entrainment within ASTM specifications for a variety of fly ash compositions.

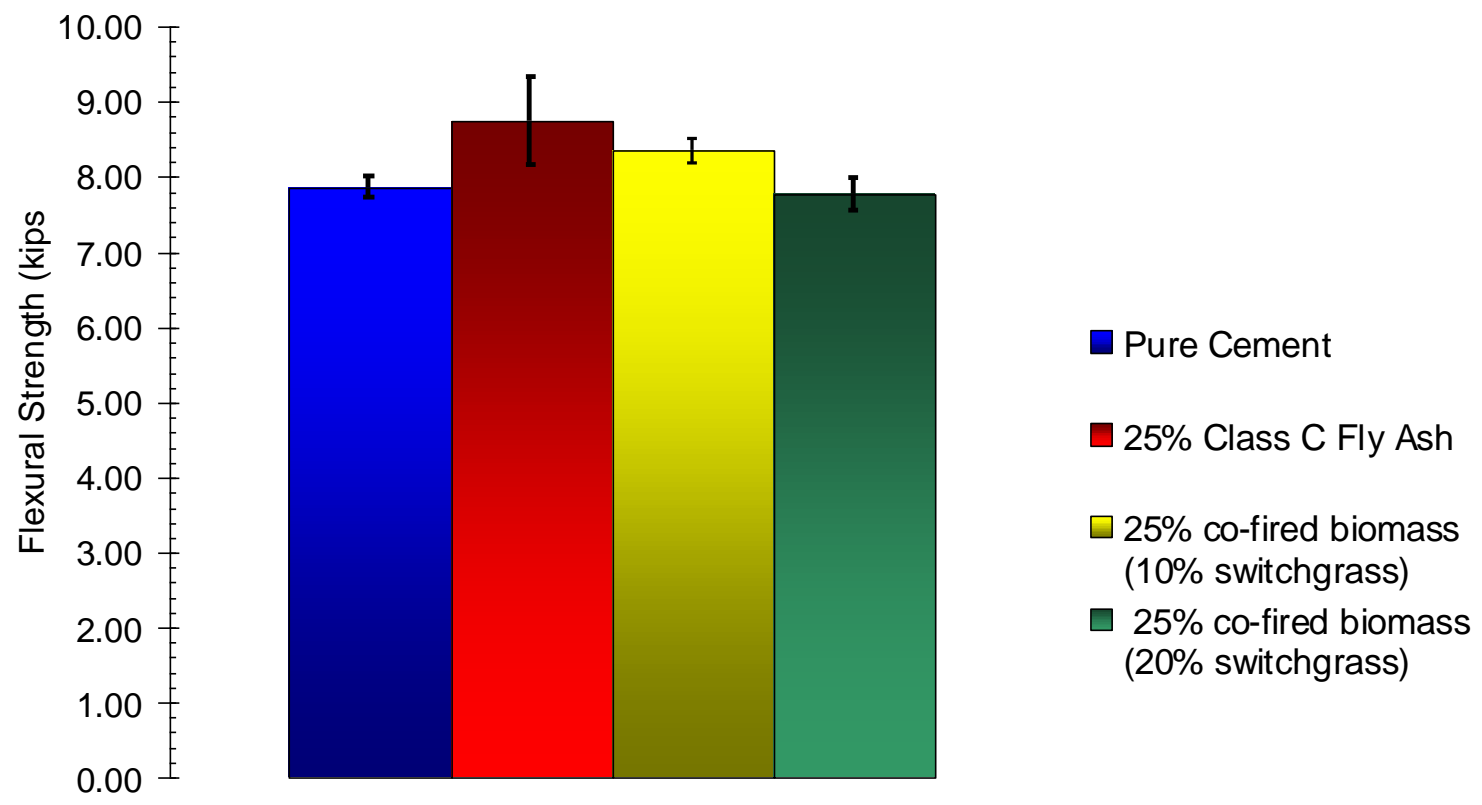

Figure 5Flexural strength and its dependence on fly ash compositon.
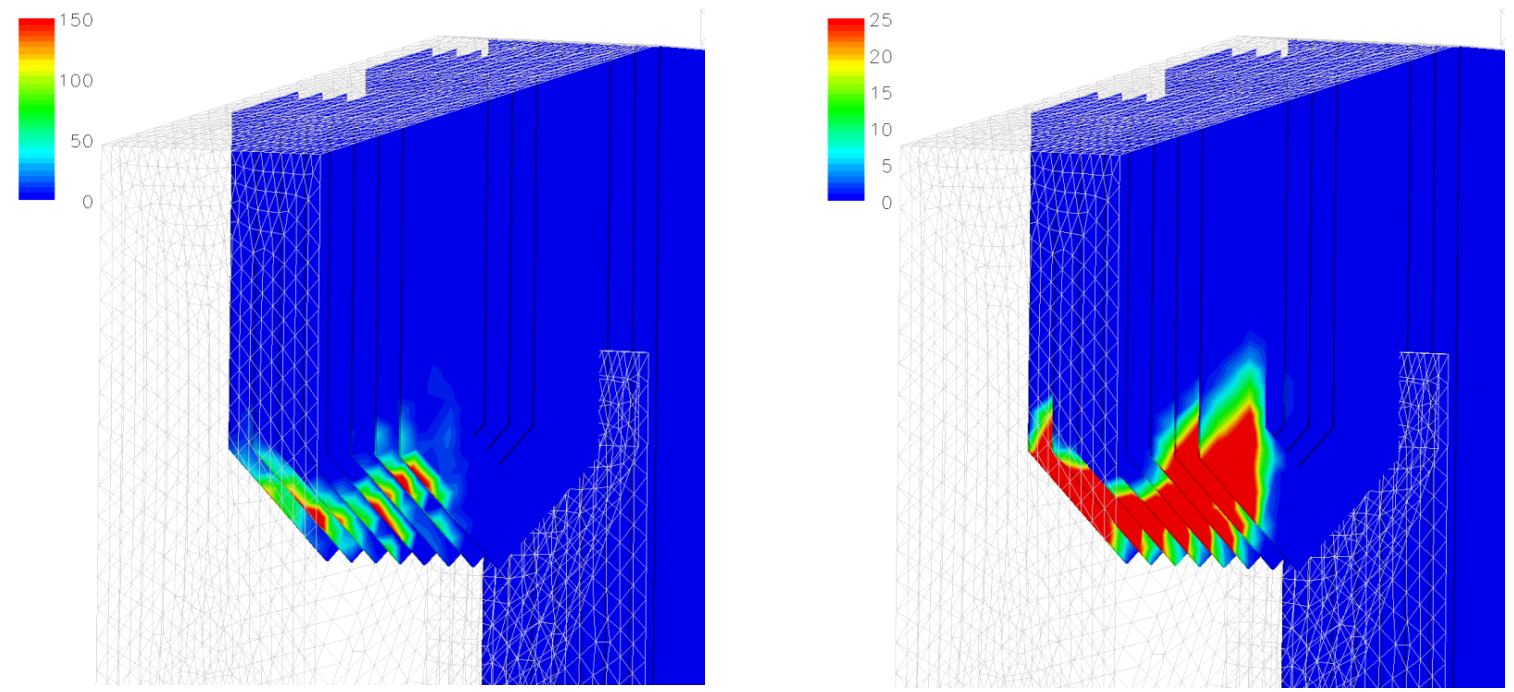

Figure 6Impacted of temperature, velocity, and gas composition striations on two major classes of deposit formation mechanisms: impaction mechanisms (left) and boundary-layer mechanisms (right). 


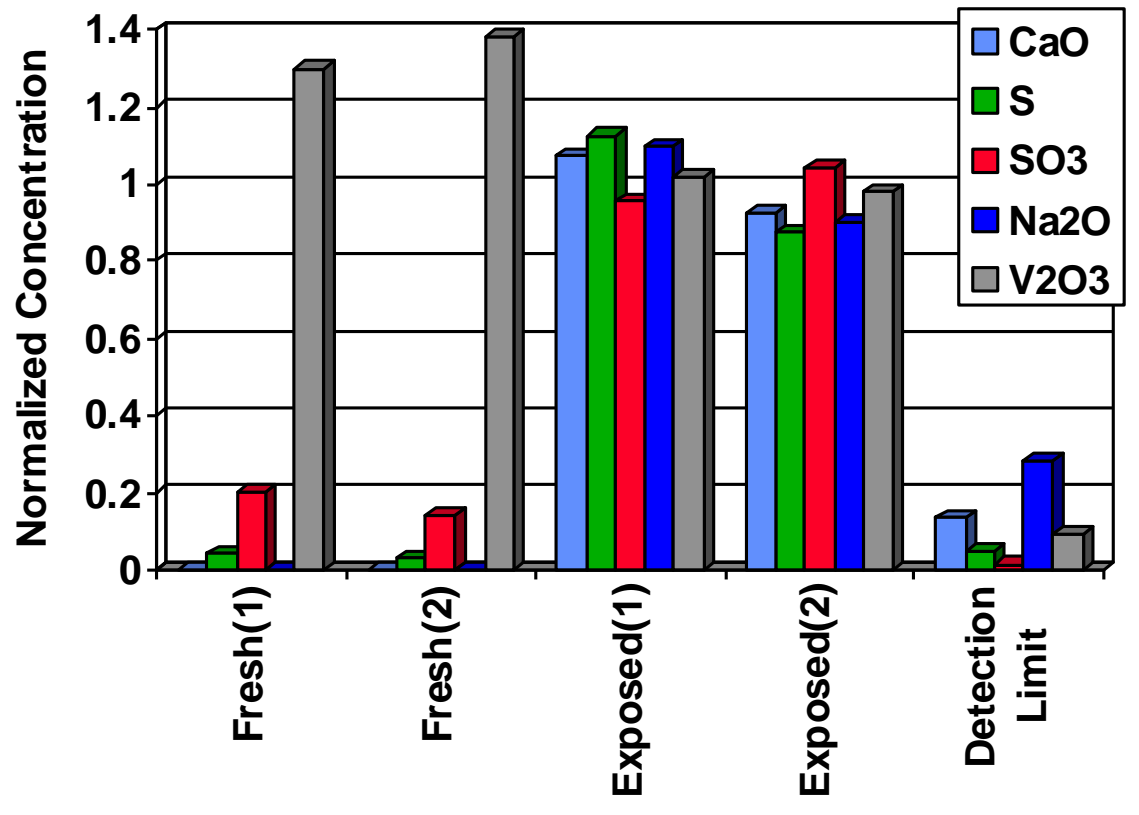

Figure 7Concentrations of key elements (reported as oxides) in pre- and post-exposed catalyst from a slip-stream reactor.

\section{References}

Baxter, L. L., M. Rumminger, T. Lind, D. Tillman and E. Hughes (2000). Cofiring Biomass in Coal Boilers: Pilot- and Utility-scale Experiences. Biomass for Energy and Industry: 1st World Conference and Technology Exhibition, Seville, Spain

Junker, H., F. Fogh, L. Baxter and A. Robinson (1998). Co-firing Biomass and Coal: Experimental Investigations of Deposit Formation. 10th European Conference and Technology Exhibition, Würzburg, Germany.8-11 June 1998

Robinson, A. L., H. Junker and L. L. Baxter (2002). "Pilot-scale investigation of the influence of coalbiomass cofiring on ash deposition." Energy \& Fuels.

Robinson, A. L., H. Junker, S. G. Buckley, G. Sclippa and L. L. Baxter (1998). Interactions between Coal and Biomass when Cofiring. Twenty-Seventh Symposium (International) on Combustion, Boulder, CO, Combustion Institute

Tillman, D. A., E. Hughes and B. A. Gold (1994). Cofiring of biofuels in coal fired boilers: Results of case study analysis. 1st Biomass Conference of the Americas, Burlingtion, VT 